\title{
The effects of electromagnetic field on the nervous system
}

\author{
Süleyman Kaplan \\ Department of Histology and Embryology, Faculty of Medicine, Ondokuz Mayls University, Samsun, Turkey
}

\section{ARTICLE INFO}

\section{Correspondence to:}

Süleyman Kaplan

Department of Histology and Embryology,

Faculty of Medicine,

Ondokuz Mayıs University,

Samsun, Turkey

e-mail: skaplan@omu.edu.tr

\section{Keywords:}

Cerebellum

Dentate gyrus

Electromagnetic field

Purkinje cell

Pyramidal cell

Stereology

\section{ABSTRACT}

The biological effects of electromagnetic field (EMF) exposure from mobile phones have caused growing concern among scientists since there are some reports showing increased risk for human health, especially in the use of mobile phones for a long period. In our previous studies we investigated prenatally the effects of 900 megahertz (MHz) EMF on nervous system. In the first study, the effects of prenatal exposure of EMF on the granule cell number in the dentate gyrus of 4-week-old rats were searched. In this experiment we used a control group and an EMF exposed group that exposed to an EMF of up to 900 $\mathrm{MHz}$ for $60 \mathrm{~min} /$ day between the first and last days of gestation. In the second study, it was investigated the number of pyramidal cells in the cornu ammonis (CA) of the 16-week-old female rat hippocampus following postnatal exposure to a $900 \mathrm{MHz}$. In this study, only EMF exposed group was exposed to $900 \mathrm{MHz}$ EMF (1 h/day for 28 days) in an exposure tube. The control group was not put into tube but the sham exposed group was. In the third study, a control group and an experimental group of pregnant rats that were exposed to an EMF were used. For obtaining EMF exposed offspring, the pregnant rats were exposed to $900 \mathrm{MHz}$ EMF during the 1-19 ${ }^{\text {th }}$ gestation days. The effects EMF exposure on the number of Purkinje cells in the cerebellum of 16 weeks old female rats were investigated. In the last study, a control group, sham exposed group and an EMF exposed group were used. At the end of the four experiments the number of cells was estimated using stereological techniques. Histopathological evaluations were also made. Results of these studies have showed that long duration exposure to $900 \mathrm{MHz}$ EMF leads to decreases of Purkinje cell numbers in the cerebellum, pyramidal cell numbers in the $\mathrm{CA}$ and granule cell number in dentate gyrus of hippocampus.

J.Exp.Clin.Med., 2013; 30: 279 